\title{
Ten Observations on Change in Technical Services
}

\author{
Sheila S. Intner
}

Technical services provides the infrastructure for organized service of all sorts in all kinds of libraries. It can be perceived as the heart of library and information work, since its central functional component is the organization of materials for use. All other services really depend to a greater or lesser degree on this key to retrieving something somebody needs from the great storehouse of knowledge contained in library collections-even in collections of relatively modest size. Furthermore, technical services comprises more than just organization, with acquisition work preceding it (one must acquire materials before they can be organized, after all) and circulation succeeding it.

There are many changes in technical services work today and the technical services librarian is expected to play a much more complex role than ever before. The following ten observations focus on these changes in order to identify and describe them, and in a small way offer suggestions about the responses likely to be effective and professionally satisfying.

\section{Ten Observations}

1. Computers play a major part in the unsettled and unstable information world today. However, the first observation is that computers are merely a change agent; accommodating them is not the purpose behind recent changes in technical service activity despite appearances to the contrary. Rather, increases in the amount of intellectual activity over several decades and the concomitant larger numbers of information products and increases in demand for library services based on those millions of pieces of informationmore than eleven million of them in OCLC-are the powerful influences behind change, along with a fearful reduction in dollars available to put to the task. The capabilities of computers, a result of technical progress occurring outside the pro-

Dr. Sheila S. Intner is Assistant Professor at the Columbia University School of Library Service in New York. Her remarks constituted the keynote address at the fall conference of the Resources and Technical Services Section, held September $26,1984$. fession-at-large, can be exploited in libraries to furnish sophisticated services previously unimaginable on any scale, with limited numbers of staff.

2. On the whole, library educators are not preparing technical service librarians properly with the skills they need to perform in this brave new real-world. Those who have been out in the field for a while have either acquired them by the seat of their pants or dropped by the wayside.

The skills they need are management skills, especially financial and personnel management, with a large dose of training in systematic, ongoing, critical analysis of processes in order to achieve improvements in the input/output ratios of their departments. We do not teach this in library school-certainly not in cataloging, not even at the advanced level, nor in most courses in technical services. Yet most people with professional library degrees working in catalog departments are expected to manage those departments in addition to doing original cataloging and classification. They are expected to plan services, organize personnel, recruit and train staff, devise and monitor budgets, and account for expenditures. All of these are management skills, not technical service skills, and they are required in addition to a thorough knowledge of technical services theory and practice.

3. Technical services has always been perceived as the most complex area of library and information service and every part of technical services has become far more complicated than ever, For example, libraries used to be concerned about standardizing local practice and exerting bibliographic control over their own collections. Now attention is focused, not on regional or national standards, but on international standards and universal bibliographic control. OCLC is in England. UTLAS is in Japan. It is not an easy task for us to think globally and act locally, as David Stam asked us to do. ${ }^{1}$

Internal consistency is not the measure of good work any more; in fact, it may represent a fatal flaw in a library operation if it is a reflection of policies that rely only on the institution's own resources to satisfy all client needs. No library can 
satisfy all or even most of its client needs alone, without tapping the vast body of knowledge it can encompass only by acting in concert with other libraries.

Think how many pages there were in Cutter's Rules for a Dictionary Catalogue or the red and green books ${ }^{2}$ compared to the 620 pages of rules and explanantions in the Anglo-American Cataloguing Rules, second edition. Yet in our complicated new world we are prodded by carrot and stick to work faster and increase our productivity. A small city library acquisition department I recently investigated dealt with more than twentyfive vendors in addition to an unknown number of publishers for direct orders. Suddenly we are buying quantities of materials in languages whose scripts we cannot read, media in formats we cannot understand, and subjects which the Dewey Decimal and Library of Congress classifications were never designed to classify.

\section{Computers are merely a change agent.}

4. Perhaps most important of all, the public catalog has finally been recognized as the important public service tool it really is; moreover, a tool for the public to use, too. Reference librarians are casting hungry glances at it if they have not already begun swallowing it down whole. What is meant is that control of the public catalog is passing out of the hands of technical service librarians in general and catalogers in particular, and into the sphere of public service staff and administrators. At one great university research library, for example, the university librarian said she was quite satisfied that the design of the proposed online public access catalog was not being left to the cataloging department, but was a library-wide project in which the reference staff were taking the lead. Some of the planning committees involved had no one from the cataloging departments on them and others had one or two out of a body of eight or nine people. If Marshall McLuhan was ever right in proclaiming that "the medium is the message," ${ }^{\prime 3}$ it is visible in what is happening in developing online catalogs for the public.

We cannot continue to change "computer software" to "machine-readable data files" for descriptive cataloging purposes, or transform other familiar everyday language into the esoteric nineteenth century terminology of subject heading lists, or any of our other arcane maneuvers. If technical service librarians had to do regular duty as bibliographic instruction librarians it would help them to understand and appreciate more fully the problems clients encounter in using the catalog. The intimate relation between technical and public service librarians is closest at the public catalog. It is our interface.

5 . The fifth observation is a corollary to the fourth: Technical service librarians are going to have to be, if they are not already, resource personnel for public service activities. Long ago, Tauber recognized the technical aspects to public service activities, which he termed the behindthe-scenes or non-public parts of circulation and reference. ${ }^{4}$ Automating circulation, for example, exposed its natural relationship to the other technical services, acquisitions and cataloging. Mitch Freedman recently discussed this in a lengthy article in Library Journal. ${ }^{5}$ If you consider circulation's dependence on bibliographic files and the host of backroom activities circulation performs, such as managing overdues and shelving materials, the public service acts of checking things out and receiving them back or of taking fine money from clients are far less dominant than its traditional public service categorization would imply. On the contrary, maintaining bibliographic and inventory control over materials which are part of automated circulation control systems are really technical service operations and we must lend our expert knowledge to the tasks.

6. Now, if They are getting control over the catalog and We are getting control over circulation, where is our nice traditional organization chart going? Into the wastebasket, I believe. If your library has this neat departmentalization, it is probably going to change with the introduction of a computer system. A new Automation Coordinator's or Supervisor's position will very likely be created, with authority and responsibility in both camps-maybe in all three camps if the organizational structure is divided, typically, into Administrative, Public and Technical Services. The Automation Coordinator is wedged in there somewhere between the Chief Executive Officer and any cohorts at the top level, and the rest of the line staff, including your run-of-the-mill reference and technical service librarians. The position is not only asymmetrical on the organization chart, it is also the focal point for interdepartmental activity. This should be perceived as positive, helpful and encouraging; but all-too-often may be received as threatening and scary, to be thwarted at all costs. If you should be catapulted into such a position, just assume all paths are mined and proceed with extreme care and sensi- 
tivity. If someone else in your library is in that position, ask yourself if you are, by mistake or unconscious design (since no technical service librarian would do it deliberately), throwing turfprotecting monkeywrenches into the action and inadvertently sabotaging multidepartmental progress.

7. One of the most complex problems in technical services today, and one with which librarians at the cutting edge of technological change are already wrestling, is how to determine the best mix of tradeoffs for their institutions, between bibliographic excellence and bibliographic expedience. Can we afford AACR2's secondlevel description, forgetting third, and extensive editing of cataloging copy, or manually-enriched subject access, or even automated additions to LCSH headings as found in the bibliographic utilities? Can clerical help be substituted for professional staff so libraries can reap the dollar benefits of shared automated cataloging without sacrificing either quantity or quality of the products and services emanating from their departments? How can one compare service potential of manual catalogs and cataloging operations with the on-line catalog? How can librarians make that leap of imagination to totally new possibilities instead of merely trying to re-create card catalogs in the new medium?

\section{The public catalog has finally been recognized as the impor- tant public service tool it really} is.

8. In order to initiate and direct the ongoing changes that will serve goals identified as constructive and appropriate, technical service librarians will have to learn to do empirical research. It is no longer enough to know what is currently working without visible problems. Now new developments will have to be monitored and experiments with new applications will have to be done without waiting for their imposition from outside the technical services department, or from outside the library, or from outside the parent institution. Where, after all, did we get the computer? Certainly not from within the profession. Computers were a development from the military-industrial complex-about as remote as possible from the profession. Perhaps less extravagantly, we must examine our own operationsour acquisition routes, cataloging processes, and circulation procedures-to see where changes can result in better service or achieve cost savings, or both. The tradition of the scholar-librarian, mourned as lost in recent times, must be resurrected, but with a modern twist. The positive part of that image must be regained and revitalized and employed in the pursuit of our new objectives.

9. Cultivating the political arts of sensing strategy, influencing policy, and winning points for visibility and achievement, never a need in traditional technical service operations (which occupied the deepest, darkest, least obvious nook or cranny of a library building), should be an urgent priority in this changing world. I've seen technical service heads, under whose official authority hundreds of thousands of dollars worth of computer equipment lies, unable to exert any real control over decision-making for computer services and precious little control over hiring and promotion, even within their own shop. This came about because they failed to recognize where the real lines of authority were and did not put forth the effort to "win friends and influence people" who could help them achieve their goals. Some of my colleagues believe it is undignified or unprofessional to do more than sit back and wait to be recognized. Others are hampered by personal distaste for activities even vaguely resembling lobbying or selling their point of view. Still others fail to understand policy processes in their institution, and the never-fail value of creative funding ideas when seeking approval for important, but expensive, projects. Many are helpless in the face of a large bureaucracy. We need much more internal political sophistication and expertise. Also, we need to be willing to plunge into the fray and slug it out, toe-to-toe with other department heads using all the ideas, statistics, and logic at our disposal in order to prevail.

10. The final observation is that effective technical service librarians must recognize the wider role they can play in providing library services and helping fulfill the mission of their libraries, not only by ordering books and cataloging them on receipt, but by participating, in the fullest sense of the word, in collection development and management as well as collection use. We must come out of our cozy back rooms and work out front, on the line. We must be prepared to work with the public and with public and administrative services personnel. Is that an aggressive stance? I certainly hope so. Colleagues who perceive only the confines of their job descriptions can probably be replaced by a student aide with a computer terminal. 
The hallmark of the well-trained technical service librarian of the future will include flexibility and vision in addition to tangible evidence of personal professional development and frequent exercise of intellectual curiosity. Perhaps the greatest change in technical service activities will be the leadership provided in helping libraries to fulfill their missions. Somehow we must move from passive and reactive modes of operation to active and creative ones, which, though difficult and much more work, offer satisfying and rewarding professional careers.

\section{Postscript}

A very wise librarian writing about trauma in catalogs and cataloging in an earlier age said, "Those of us who see ourselves bridging ... two eras have an added responsibility. We know and respect what was good in the past. We honor the traditions in which to greater or less extent we participated. And for such reasons our leadership in charting new courses should and can be so much the wiser." Those were Andrew Osborn's words in his famous article, "The Crisis in Cataloging." A little more than twenty years later, Ruth

\section{We must come out of our cozy back rooms and work out front, on the line.}

French Strout said, "The enormous and still increasing proliferation of publications is of course central to the matter of both the format and the function of the catalog."7 These venerable librarians recognized and articulated problems that sound familiar now-Osborn decrying the unnecessary complexity of cataloging codes and practices emphasized simplicity, but simplicity with discipline in the form of practical and flexible standards. Strout, with the words above, introduced a 1964 conference focusing on Changing Dimensions of the Catalog when only the tip of the iceberg was visible.

The best, for technical services, is yet to beproviding we can make it so.

\section{References}

1. David H. Stam, "Think Globally-Act Locally: Collection Development and Resource Sharing," Collection Building 5 (Spring 1983):18-21.

2. Charles A. Cutter, Rules for a Dictionary Catalogue (Washington: Government Printing Office, 1876); Catalog Rules: Author and Title Entries (Chicago: American Library Association, 1908), called "the red book"; Rules for Descriptive Cataloging in the Library of Congress (Washington: The Library, 1949), called "the green book." The 2nd edition of the "red book," known as the ALA or 1949 rules, was a much expanded version: $A$. L. A. Cataloging Rules for Author and Title Entries, 2nd ed. (Chicago: ALA, 1949).

3. Marshall McLuhan, Understanding the Media: The Extensions of Man (New York: McGraw-Hill, 1964), vii, 7-21.

4. Maurice F. Tauber, et al. Technical Services in Libraries (New York: Columbia University Press, 1954), 1.

5. Maurice J. Freedman, "Automation and the Future of Technical Services," Library Journal 109 (June 15, 1984): 1197-1203. 6. Andrew Osborn, "The Crisis in Cataloging," Library Quarterly (Jan., 1941): 393-411.

7 Ruth French Strout, "Introduction," Library Quarterly (Jan., 1964):1.

\section{NCLA Scholarships}

The North Carolina Library Association administers three funds which assist students of library science who are residents of North Carolina.

The North Carolina Library Association Memorial Scholarship is a $\$ 1000$ scholarship for any type of study in library science. The QueryLong Scholarship is a $\$ 1000$ scholarship for a student who plans to work with children or young adults. The McLendon Student Loan Fund awards loans at a low rate of interest.

All of these funds are available for original or continued study in library science and may be awarded to a student enrolling in library school for the first time, to a student currently enrolled in a library school, or to a practicing librarian who wishes to pursue additional studies.

To be eligible, the applicant must have been a legal resident of North Carolina for at least two years and must hold an undergraduate degree. In addition, the applicant must have been accepted by a library school and should demonstrate both a genuine interest in professional library work and a need for financial assistance.

In 1984, the Memorial Scholarships were awarded to Charles Harmon of Thomasville and Elinor Vaughan of Winston-Salem. The QueryLong Scholarship was awarded to Susan Annette Hall of Wilmington. In addition, two loans of $\$ 300$ each were made from the McLendon Fund.

Applications for 1985 Scholarships are due March 1, 1985. For application forms and further information, contact:

Sheila A. Core, Chairman

NCLA Scholarship Committee

Surry Community College Library

P. O. Box 304

Dobson, North Carolina 27017

Telephone:

Home: 919-386-4195

Work: 919-386-8212, ext. 259 